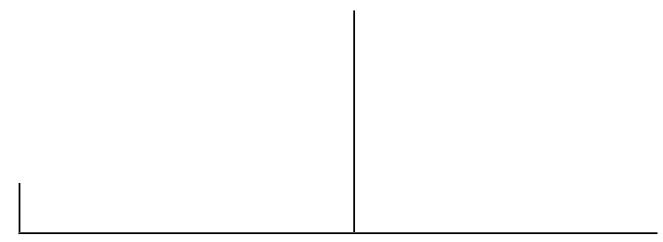

Rev. Latinoam. Psicopat. Fund., São Paulo, v. 15, n. 4, p. 838-850, dezembro 2012

\title{
método psicanalítico de pesquisa e a clínica: reflexões no contexto da Universidade*
}

\author{
Nadja Rodrigues de Oliveira \\ Maria Izabel Tafuri
}

Este artigo reflete sobre a pesquisa e a escrita em psicanálise na universidade. São desenvolvidas reflexões críticas sobre o método psicanalítico no cenário acadêmico, as estratégias metodológicas de pesquisa em psicanálise, o lugar do analista-pesquisador neste processo, e as implicações da escrita em psicanálise.

Palavras-chave: Método psicanalítico, Universidade, construção de caso, pesquisa

* Artigo baseado em capítulo da dissertação de mestrado de Nadja Rodrigues de Oliveira, intitulada "Costurando rupturas: o trauma na clínica psicanalítica com uma criança”, defendida em 12 de agosto de 2011 na Universidade de Brasília - UnB (Brasília, DF, $\mathrm{Br})$. 
A partir da experiência de pesquisa em psicanálise no contexto de mestrado acadêmico, nos deparamos com algumas questões referentes ao uso do método psicanalítico e de casos clínicos na academia, assim como à escrita em psicanálise neste âmbito. Estas questões impulsionaram reflexões sobre as particularidades deste método e sua prática na Universidade, assim como sobre o lugar do pesquisador-analista-escritor neste processo.

O método psicanalítico de pesquisa, diferentemente dos métodos qualitativos e quantitativos, possui particularidades que o inserem em outra lógica de pesquisa. Estas diferenças da psicanálise com relação ao que é geralmente concebido como científico têm trazido discussões diversas sobre sua cientificidade, as quais remontam à época em que Freud publicou $A$ interpretação dos sonhos e se estende por todo o século XX (Bianco, 2003).

Podemos destacar dois pontos essenciais em que o método psicanalítico difere daqueles usualmente utilizados na academia, geralmente guiados pelo positivismo científico que caracteriza a maioria das produções científicas a partir do século XIX. São eles o fato da pesquisa em psicanálise não envolver, em seus objetivos, uma inferência generalizadora de seus resultados para uma amostra ou uma população, e a constatação de que sua estratégia de análise do material clínico é sobre os significantes e não os signos (Iribarry, 2003).

Pinto (1999) demarca que talvez a maior dificuldade para a academia, quanto à psicanálise, seja o fato de que seu objeto, $\mathrm{o}$ inconsciente, nunca se deixa conhecer de fato. Na verdade, o autor comenta que a psicanálise provavelmente só se sustentou até os dias atuais neste mundo tão objetivante por conta da tradição científica de Freud, a qual pode ser notada por meio de sua preocupação com exatidão, não contradição e na demonstração dos conceitos. Por outro lado, Freud é confrontado pelo próprio saber psicanalítico ao valorizar o fato de que o progresso do conhecimen- 
to não se relaciona com a ideia de rigidez, sendo necessário maleabilidade teórica e conceitual (Bianco, 2003). Esta flexibilidade da teoria se sustenta na clínica psicanalítica, a qual ocupa, no caminho traçado por Freud, o lugar de via de construção do saber metapsicológico (Berlinck, 2002), caracterizando a psicanálise como uma área de conhecimento e, acima de tudo, uma terapêutica (Celes, 2005).

Freud (1913) já afirmava que, em psicanálise, tratamento e investigação coincidem. Seu percurso na fundação deste campo é marcado por motivação advinda da prática clínica, caracterizando a investigação científica em psicanálise como derivada da singularidade dos casos clínicos e própria à prática psicanalítica. Assim, podemos pensar a psicanálise em si como um método de pesquisa, mesmo quando não imersa na universidade.

Tendo em vista a coincidência entre clínica e pesquisa, ao inserirmos o método psicanalítico no contexto acadêmico, acreditamos ser inevitável também a inserção do uso da prática clínica como ferramenta investigativa. Uma vez que Freud partiu da clínica a fim de desenvolver sua metapsicologia, e tendo em vista o objeto de estudo da psicanálise - o inconsciente, o qual apenas pode ser circunscrito na situação de análise -, a psicanálise como pesquisa tem na clínica seu ponto principal de apoio (Bianco, 2003).

Neste sentido, Caon (2000) traça um paralelo entre a clínica psicanalítica e a pesquisa. $\mathrm{O}$ autor destaca que, se a clínica psicanalítica se caracteriza pela prática da associação livre por parte do analisando em alteridade com o analista, o pesquisador em psicanálise também o pratica, mas frente à alteridade da teoria psicanalítica. Em outras palavras, ele aponta para a importância da transferência tanto no processo de análise quanto na pesquisa em psicanálise.

O caráter clínico do método psicanalítico implica a transferência como fator que promove a pesquisa neste campo. Uma vez que este conceito caracteriza e viabiliza o acontecer do inconsciente, sendo essencial ao processo de análise, podemos dizer que, de uma forma ou de outra, a transferência é a principal via de investigação em psicanálise. A pesquisa se inicia por meio da transferência, uma vez que ela coloca "o psicanalista num lugar muito específico que é o lugar de um não-saber a respeito de um enigma" (Berlinck, 2002, p. 3).

Na clínica psicanalítica, podemos dizer que um tipo de pesquisa pela transferência já se faz presente por meio do analisando que realiza, a partir da transferência promovida pela alteridade do analista, uma investigação sobre sua própria vida (Iribarry, 2003). Entretanto, vale lembrar que, ao se falar da transferência analista-analisando, não estamos falando de uma verdade contida no inconsciente do analisando que "vem à tona" por meio de sua relação com o analista, assim como tampouco nos referimos a um saber já presente no analista. $\mathrm{Na}$ verdade, "ambos, analista e analisando, são pesquisadores-produtores dessa 


\section{ARTIGOS}

verdade" (Garcia-Roza, 1994, p. 10), cada um ocupando um lugar diferente e específico neste processo.

Contudo, a pesquisa realizada pelo analisando e aquela desenvolvida pelo analista partem de lugares diferentes e possuem rumos distintos. Enquanto o analisando desenvolve um processo de investigação sobre si com finalidade terapêutica, o analista busca, por meio das construções sobre a prática clínica, elaborar hipóteses metapsicológicas. É possível, entretanto, pensar um paralelo quanto a estes lugares: se o analisando ocupa o lugar de protagonista em sua pesquisa sobre a própria vida, o analista, ao desenvolver uma pesquisa em psicanálise, se coloca como primeiro sujeito dela. Neste lugar, ele produz uma investigação sob o testemunho de um outro, de uma alteridade com quem também vai "transferenciar" (Iribarry, 2003).

Citamos acima o papel da própria teoria psicanalítica como lugar de alteridade (Caon, 2000), mas consideramos importante levarmos em conta também as demais e diversas figuras que ocupam este lugar. Sua importância se justifica pelo fato delas também serem alteridades com as quais o pesquisador estabelece uma transferência, constituindo aspectos que influenciam o processo de pesquisa e de escrita em psicanálise. Elas envolvem desde a instituição universitária que acolhe a pesquisa até o orientador no processo de escrita.

Refletindo sobre as alteridades envolvidas na produção e no destino da pesquisa em psicanálise, Iribarry (2003) resgata a função de Fliess no desenvolver das pesquisas freudianas. Segundo a autora, Fliess ocupava um lugar de alteridade que acolhia os achados metapsicológicos de Freud, de forma a elogiá-los e criticar (Publikum). Neste sentido, podemos pensar o lugar do orientador acadêmico, e mesmo da banca na defesa, como sendo as alteridades a que se entrega a pesquisa feita, e como um dos pontos de transferência no processo de construção de uma pesquisa em psicanálise.

Moura e Nikos (2001), fazendo referência às ideias de Fédida, destacam que há dois públicos essenciais a que o pesquisador psicanalítico se dirige. O primeiro (Publikum) seria a banca da defesa de mestrado ou doutorado, e o segundo (Veröffentlichkeit) as futuras publicações a partir da defesa. Assim, a escrita em psicanálise implica o pesquisador inclusive na forma como ele se relaciona com estes lugares de alteridade a que dirige sua escrita.

Uma vez que a transferência é o principal instrumento de pesquisa em psicanálise, destacamos o alto grau de implicação daquele que se aventura a pesquisar neste campo. Afinal, o pesquisador instrumentaliza uma transferência estabelecida entre ele e um analisando a fim de produzir um saber metapsicológico (Iribarry, 2003) e, ao mesmo tempo, instaura uma transferência com o texto produzido e com as alteridades a quem ele será exposto - o orientador, a comunidade acadêmica, a banca na defesa etc.

Rev. Latinoam. Psicopat. Fund., São Paulo, v. 15, n. 4, p. 838-850, dezembro 2012 
Como comenta Lacan (1964), "a transferência é um fenômeno em que estão incluídos, juntos, o sujeito e o psicanalista" (p. 219). Assim, a pesquisa e a escrita em psicanálise são caracterizadas pela singularidade da narrativa construída, a qual contém a marca do inconsciente do autor (Birman, 2001). Esta marca se faz pela própria atividade de escrita - sempre endereçada a um outro (Delorenzo et al., 2000) - e pela narrativa construída acerca de uma transferência ocorrida na clínica. Neste sentido, a escrita em psicanálise não é coerente com o modelo positivista de ciência ou com a escrita sem expressão de afeto, impessoal e neutra geralmente presente na academia.

Para que a pesquisa não se perca nesta singularidade, tendo em vista a alta implicação do pesquisador no processo de investigação e no material analisado, é importante que exista o espaço de análise do próprio pesquisador. Como Safra (1993) pontua, a análise do próprio analista é a forma de promover um espaço de investigação diferenciado dos processos pessoais do pesquisador, em especial quanto a esta parte do material clínico.

Desta maneira, a pesquisa em psicanálise ocorre de forma a inferir a implicação do autor na investigação e na escrita referente a ela, de forma a ser importante que o pesquisador leve em consideração este seu lugar no estudo desenvolvido. Isto envolve questões como a pessoa pronominal que desenvolve a narrativa - utilizar a primeira pessoa no lugar da terceira pessoa passiva, que caracteriza a maior parte da escrita na academia -, assim como a clareza do pesquisador-escritor sobre seu lugar frente às diversas transferências implicadas na atividade de pesquisa e de escrita em psicanálise.

Além disso, partindo da clínica como motivação e via de desenvolvimento, uma pesquisa em psicanálise pode utilizar casos clínicos de diferentes formas, a depender da estratégia metodológica escolhida. Há uma diversidade de estratégias possíveis ao fazermos uso de um caso clínico, as quais trazem implicações diferenciadas para o trabalho produzido e implicam compreensões distintas sobre o papel do caso na pesquisa. Atualmente, dentre as estratégias de pesquisa encontradas em estudos acadêmicos psicanalíticos, se destacam o estudo de caso e a construção do caso. Enquanto a primeira é frequentemente utilizada por outras áreas da ciência, a segunda é mais característica a um trabalho propriamente psicanalítico (Moura \& Nikos, 2001).

O estudo de caso tende a ser uma comunicação de uma experiência de forma dialogada com uma teoria escolhida, com a finalidade de corroborar, ilustrar, contrastar ou levantar questionamentos sobre ela. Nesta estratégia, há uma delimitação conceitual sobre o que será o objeto da investigação, e a narrativa desenvolvida sobre o caso geralmente segue uma ordem cronológica: primeiro apresenta-se as informações acerca da história de vida do paciente e, em seguida, algumas sessões e o percurso do tratamento (Moura \& Nikos, 2001). 


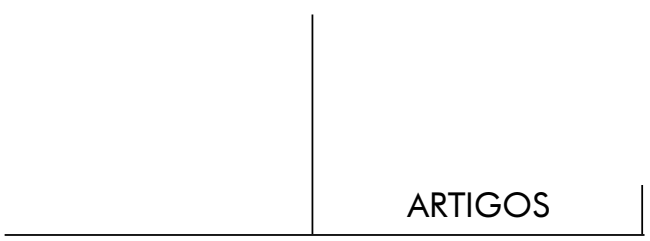

Este formato, segundo Moura e Nikos (2001), é herança da tradição psiquiátrica de Freud, o qual introduziu um estilo de relatar documentalmente as sessões e evoluções dos pacientes nos casos clínicos promotores de sua metapsicologia. Contudo, os autores salientam que, nesta estratégia metodológica, cada caso possui caráter singular, não sendo generalizáveis as ações terapêuticas em si (interpretações etc.) e seus efeitos, uma vez que dizem respeito a uma experiência situada em uma relação específica analista-analisando.

Entretanto, o caso clínico em psicanálise não tem como objetivo retratar a pessoa do paciente, sua história prévia, ou mesmo o contexto da análise em um sentido objetivante e de pretensa amostragem do que socialmente se chama "realidade". Em outras palavras, o caso clínico não deve buscar reconstruir a história do paciente de forma a obturar buracos e compreender o que de fato ocorreu em um sentido biográfico. Na verdade, o caso clínico psicanalítico se preza a exatamente àquilo que falta, que escapa: à falta constituinte e fecunda do sujeito (Caon, 2000). Desta maneira, Caon destaca que a construção do caso clínico implica a estruturação de um discurso que não coincide nem com o psicológico e nem com o médico, remetendo a uma ficção e teorização metapsicológica do pesquisador em psicanálise.

Esta estratégia metodológica, em contraste com o estudo de caso, não implica uma realidade psicológica narrada por meio de uma história clínica cronológica. Na verdade, a construção do caso envolve a elaboração de uma hipótese metapsicológica advinda do encontro entre analista e analisando, naquilo que se situa, para o analista, como uma experiência estranhamente familiar (Moura \& Nikos, 2001).

Evocando Fédida, Moura e Nikos destacam que, a fim de construir um caso, é preciso que o analista reflita sobre sua contratransferência tendo em vista não só a psicopatologia do paciente, mas também sua dimensão trans-subjetiva, apontando para sua própria compulsão à repetição e sua impossível resposta à fala do paciente. Neste sentido, a fim de construir um caso, há de se incluir o trabalho do mesmo no contexto da supervisão.

Esta seria a maior diferença entre o estudo de caso e a construção do caso (Moura \& Nikos, 2001). Se no primeiro bastaria a teoria a fim de confirmar ou não a dimensão empírica da clínica apresentada, na construção do caso, "a análise de supervisão é instauradora e constitutiva daquilo que se pode chamar de um caso na psicanálise" (Fédida, 1992, p. 231). O supervisor cumpre, assim, a função de alteridade a partir da qual o caso pode ser construído. Na verdade, um ponto que caracteriza a construção de um caso é o uso da transferência com o analisando e com o supervisor como instrumentos para esta construção (Iribarry, 2003).

Rev. Latinoam. Psicopat. Fund., São Paulo, v. 15, n. 4, p. 838-850, dezembro 2012 
É interessante também salientar o ponto de vista de Fédida (1992) de que, na construção do caso, não é uma temática que faz do caso atendido um caso clínico, mas sim o fato de que o "analista só começa a saber que o paciente tornar-se-á 'um caso de análise' em razão mesmo do recalque que sua fala provoca nele, no próprio decorrer das sessões" (p. 217). É o desenvolvimento da relação analítica, reconstruída na supervisão, que constrói o caso, e não uma teoria a ser ilustrada. Uma vez que a clínica reconstruída não segue ordem cronológica, mas sim lógica, o mesmo se aplica à construção do caso (Moura \& Nikos, 2001).

Queiroz (2002), comentando os estilos de escrita de caso clínico na história da psicanálise, destaca que o caminho percorrido foi do descritivo ao "performático", que se refere ao que estamos chamando aqui de "construção do caso". Este estilo coloca o foco na relação transferencial analista-analisando, e não no sujeito em análise, minimizando a importância das categorias nosográficas no saber clínico. Assim, ao construir um caso, produz-se um relato que não se reduz à experiência em si ou à teoria envolvida, mas sim uma ficção marcada pela transferência cujos personagens são sustentados por eventos e pessoas reais. A escrita do caso não encerra a pesquisa psicanalítica nele implicada (Queiroz, 2005).

Como afirma Chiantaretto (conforme citado em Caon, 2000) ao se referir ao caso de Serguéi Pankejeff, este caso se assemelha a uma boneca russa, de forma a esconder sempre outro caso dentro dele. Em outras palavras, um analista pode traçar diversas construções a partir de um mesmo caso, como percebemos com a escrita de Freud em "História de uma neurose infantil" (1918), assim como diferentes analistas podem construir diferentes casos clínicos, apesar de terem como base um mesmo paciente (Freud e Ruth Brunswick, no caso do "Homem dos lobos"). Desta forma, percebe-se que o encerramento de uma análise não implica o término do caso clínico ou de suas construções. Na verdade, o término de um processo analítico conclui um tratamento, mas o caso clínico permanece vivo enquanto for fonte de reflexões metapsicológicas, o que insere o lugar da pesquisa por meio da clínica.

Neste sentido, nota-se que a pesquisa, a partir de casos clínicos, ocorre em cenário não necessariamente coincidente com o período do tratamento. Na verdade, podemos dizer que a construção de um caso clínico só é possível em momento posterior ao atendimento, o que foi indicado, de certa forma, quando destacamos o papel da supervisão neste processo. Segundo Caon (2000), o caso clínico construído pelo pesquisador é o relance metapsicológico do discurso do analisando, o qual foi primeiro lançado como formações do inconsciente no contexto da análise. O autor fala de "relance" como referente ao Nachträglichkeit 
freudiano, utilizado nas traduções como "só-depois", "posteriormente", e "a posteriori" (Hanns, 1996).

Neste sentido, podemos pensar a construção do caso clínico como as construções metapsicológicas do analista ocorridas na tensionalidade do só-depois que reestrutura os eventos clínicos passados, trazendo o discurso do analisando sob uma ótica metapsicológica. Acreditamos que haja diversos relances do caso tanto na clínica quanto no processo de pesquisa em psicanálise. Há um primeiro relance por meio das anotações referentes às sessões realizadas. Depois, outros relances advindos das construções ocorridas no espaço de supervisão. Mais ainda, o discurso do analisando é relançado inúmeras vezes no processo de construção de uma dissertação de mestrado em psicanálise, por exemplo.

Nota-se, assim, que a escrita do caso configura um primeiro exercício metapsicológico sobre ele, ocorrido no cenário do só-depois. Este a posteriori, assim como a presença de um terceiro - o papel no qual se desenvolve o relato da sessão, o supervisor, o orientador -, parece promover ao analista a possibilidade de se diferenciar e se retirar, em certa medida, da cena da transferência, sendo possível desenvolver construções sobre ela.

É interessante notar o valor da escrita no processo de construção do caso e pesquisa em psicanálise. É perceptível seu valor organizador enquanto a posteriori que promove a pesquisa metapsicológica sobre o material clínico. A escrita no cenário da clínica comparece como momento de elaboração das experiências transferenciais, possuindo importância tanto na condução do caso clínico quanto na produção de conhecimentos a partir dele.

De acordo com Delorenzo et al. (2000), a escrita para o psicanalista "é tentar dominar uma experiência difícil de dizer, seja por seu efeito de excesso ou pela impressão de um vazio. É tentar apoderar-se de algo, cercar, imprimir, inscrever, tanto o que o obceca, como o que lhe escapa" (II 20, grifos nossos). É quase como se a clínica fosse "traumática" e necessitasse da escrita como via de representação e de integração da experiência.

Neste sentido, Berry (1996/2005) descreve a função da escrita como organizadora e integradora da sua experiência junto a uma analisanda psicótica, havendo um cunho catártico e elaborativo nesta atividade. A escrita lhe possibilitou "ligar as imagens em frases" (Mezan, 2005, p. 237), levando à representação o acúmulo de "sufocamentos que não tinham podido ser simbolizados" (Berry, $1996 / 2005$, p. 233). Segundo a autora, "sem o trabalho da escrita eu teria ficado fechada, sufocada, paralisada" (p. 224).

Nesta citação de Berry (1996/2005), destaca-se o caráter potencialmente excessivo e paralisador do pensamento do analista relativo à experiência clínica - o seu teor potencialmente "traumático". Desta maneira, é interessante pensar sobre o valor da escrita enquanto possibilidade de inscrição e representação dos 
excessos experimentados na clínica em um momento só-depois. Isto é verdadeiro em especial em face de analisandos em que se nota a presença intensa e preponderante de angústias precoces, de cunho psicótico. Isto também ocorre na experiência de observação de bebês (Bick, 1948/1967), método utilizado a fim de favorecer a formação do analista em diversas sociedades de psicanálise.

Segundo Houzel (1989), é frequente que o observador de bebês tenha dificuldades em realizar as anotações referentes à observação, tendo em vista a grande intensidade emocional envolvida na experiência junto ao bebê e sua família. De acordo com o autor, por muitas vezes é difícil escrever sobre o que se passou, pois a escrita pode incorrer na impressão de um achatamento da vivência, de uma aplanação da intensidade emocional daquilo que foi vivido.

Neste sentido, a necessidade de escrever sobre o ocorrido se faz ainda mais importante. Traçando um paralelo entre as três funções com que Freud (1911/ 1996) define a atividade do pensamento e os três momentos da observação de bebês - que, poderíamos complementar, coincidem também com os três momentos do trabalho psicanalítico na clínica - Houzel (1989) destaca que a observação equivale ao momento da atenção, que as anotações correspondem à função de memória, e que a supervisão faz paralelo com a função de julgamento. De acordo com o autor, o respeito a estes três tempos configura um aprendizado no sentido de contrapor os efeitos perturbadores do excesso emocional da experiência de observação - e, a nosso ver, também da clínica - sobre nossa atividade de pensamento.

Retomando a escrita da clínica no cenário da pesquisa psicanalítica, podemos refletir sobre o que leva um analista a relançar um caso clínico, de forma a escrever e elaborar construções sobre ele. Se a clínica se apresenta como potencialmente "traumática", o conceito de trauma comparece na teoria psicanalítica em duas vertentes: uma que remete à angústia associada à formação de sintomas e à psicopatologia, e outra que endereça uma angústia impulsionadora no sentido da constituição psíquica. A escrita da clínica no atendimento e na pesquisa em psicanálise, então, parece ser uma via de transformação do excesso emocional das experiências clínicas em representações e produções, promovendo o desenvolvimento científico em psicanálise, assim como pessoal do analista.

Tendo em vista estas reflexões, notamos o quanto a pesquisa por meio do método psicanalítico envolve de forma íntima a prática clínica e requer a implicação do pesquisador no saber produzido. Afinal, o pesquisador ocupa também os lugares de analista e de escritor de uma narrativa neste processo, invocando a necessidade de posicionamento ativo frente às questões que estes lugares o colocam. Por exemplo, há de se posicionar frente à função da escrita do caso, às diversas transferências envolvidas na pesquisa, às motivações advindas da experiência clínica, a quem se dirige o estudo produzido etc. 
Ao inserirmos este método no contexto acadêmico, algumas problemáticas se acentuam e são acrescidas de particularidades deste meio, como o trabalho de construção de caso a partir de uma temporalidade imposta externamente, os requisitos referentes à ideia de "cientificidade" na pesquisa e na escrita, dentre outros. Neste sentido, consideramos importante que o pesquisador em psicanálise na Universidade tenha em mente esta diversidade de questões a fim de ocupar um lugar implicado e bem posicionado frente à produção de conhecimento a que se propõe, inclusive quanto ao uso do caso clínico.

\section{Referências}

Berlinck, M. T. (2002). Considerações sobre a formulação de um projeto de pesquisa em psicanálise. In Berlinck, M. T. (Org.). Psicopatologia Fundamental. São Paulo: Escuta. Recuperado em 10 novembro 2010, do http://www.uff.br/ labpsifundamental/biblioteca_biblio.htm

Berry, N. (2005). A experiência de escrever. In Mezan, R. (Org.). Escrever a clínica (pp. 217-233). São Paulo: Casa do Psicólogo. (Trabalho original publicado em 1996).

Bianco, A. C. Lo (2003). Sobre as bases dos procedimentos investigativos em psicanálise. Psico-USF, 8(2), 115-123, dez.

Birman, J. (2001). A escrita em psicanálise. In Bartucci, G. (Org.). Psicanálise, literatura e estéticas de subjetivação (pp. 185-196). Rio de Janeiro: Imago.

Caon, J. L. (2000). Retrato, auto-retrato e construção metapsicológica de Serguéi Constantinovitch Pankejeff, o "Homem dos lobos". Pulsional Revista de Psicanálise, São Paulo, 13(140/141), 22-44.

Celes, L. A. (2005). Psicanálise é o nome de um trabalho. Psicologia Clínica, 17(3), 157171 , jan.

Delorenzo, R. M. T. et al. (2000). Narrar a clínica. Percurso, São Paulo, 25. Recuperado em 6 outubro 2010 do http://www2.uol.com.br/percurso/main/pcs25/debate25.htm

Fédida, P. (1992). Nome, figura e memória: a imagem na situação psicanalítica. São Paulo: Escuta.

Freud, S. (1996). Formulações sobre os dois princípios do funcionamento mental. In Edição Standard Brasileira das Obras Psicológicas Completas de Sigmund Freud (Vol. XII). Rio de Janeiro: Imago. (Trabalho original publicado em 1911).

Freud, S. (1996). Recomendações aos médicos que exercem a psicanálise. In Edição Standard Brasileira das Obras Psicológicas Completas de Sigmund Freud (Vol. XII). Rio de Janeiro: Imago. (Trabalho original publicado em 1913). 
Garcia-Roza, L. A. (1994). Os amantes da Sophia: Escuta e releitura. Psicologia e Psicanálise, 6(1), 9-13.

Garcia-Roza, L. A. (1998). Introdução à metapsicologia freudiana. Rio de Janeiro: Zahar.

Hanns, L. A. (1996). Dicionário comentado do alemão de Freud. Rio de Janeiro: Imago.

Houzel, D. (1989). Penser les bébés - Réflexions sur l'observation des nourrissons. Revue de Médecine Psychosomatique, 19, 27-38.

Iribarry, I. N. (2003 janeiro/junho). O que é pesquisa psicanalítica? Ágora, 6(1), 115-138.

Lacan, J. (1985). O seminário. Livro 11. Os quatro conceitos fundamentais da psicanálise. Rio de Janeiro: Jorge Zahar. (Trabalho original publicado em 1964).

Mezan, R. (2005). Contratransferência, catarse e elaboração. In R. Mezan (Org.). Escrever a clínica (p. 217-252). São Paulo: Casa do Psicólogo.

Moura, A. \& Nikos, I. (2001). Estudo de caso, construção do caso e ensaio metapsicológico: da clínica psicanalítica à pesquisa psicanalítica. Pulsional Revista de Psicanálise, 13(140/141), 69-76.

Pinto, J. M. (1999). A instituição acadêmica e a legitimação da vocação científica da psicanálise. Psicologia Reflexão e Crítica, Porto Alegre, 12(03). Recuperado em 5 outubro 2010 do http://www.scielo.br/scielo.php?script=sci_arttext\&pid= S010279721999000 300009\&lng=en\&nrm=iso

Queiroz, E. F. (2002). O estatuto do caso clínico. Pulsional Revista de Psicanálise, 15(157), 33-40.

Queiroz, E. F. (2005). Inclinar-se para a escuta e inclinar-se para a escrita. Pulsional Revista de Psicanálise, 18(184), 60-64.

\section{Resumos}

(The psychoanalytic method of research and clinical practice: reflections in the university context)

In this article the author reflects on psychoanalytic research and writing in the university. Critical reflections are presented regarding the psychoanalytic method in the academic world, methodological strategies in psychoanalysis, the place of the analyst-researcher in this process, and the implications of writing in psychoanalysis.

Key words: Psychoanalytical method, University, case construction, research 
(La Méthode Psychanalytique de Recherche et la Clinique: Réflexions dans le Contexte Universitaire)

Cet article se penche sur la recherche et l'écriture de la psychanalyse à l'université. Nous développons des réflexions critiques sur la méthode psychanalytique courante dans le domaine universitaire, les stratégies méthodologiques de la recherche en psychanalyse, la place de l'analyste-chercheur dans ce processus et sur les implications de l'écriture de la psychanalyse.

Mots clés: Méthode psychanalytique, université, construction du cas, recherche

(El Método de Investigación Psicoanalítica y la Clínica: Reflexiones en el Contexto de la Universidad)

En este artículo se reflexiona sobre la investigación y la escrita del psicoanálisis en la universidad. Se desarrollan reflexiones críticas sobre el método psicoanalítico en el ámbito académico, las estrategias metodológicas de la investigación en psicoanálisis, el lugar del analista-investigador en este proceso, y las implicaciones de la escrita en psicoanálisis.

Palabras clave: Método psicoanalítico, Universidad, construcción del caso, investigación

(Die psychoanalytische Untersuchungsmethode und die Klinik: Reflexionen im Kontext der Universität)

In diesem Beitrag wird über die Untersuchung und die schriftliche Abhandlung psychoanalytischer Themen an der Universität reflektiert. Es werden kritische Reflexionen über die psychoanalytische Methode im akademischen Rahmen, über die methodologischen Forschungsstrategien im Bereich der Psychoanalyse, über die Stellung des analysierenden Forschers in diesem Prozess sowie über die Implikation der Schrift in der Psychoanalyse angestellt.

Schlüsselwörter: Psychoanalytische Methode, Universität, Fallstrukturierung, Forschung

Citação/Citation: Oliveira, N.R. de e Tafuri, M.I. (2012, dezembro). O método psicanalítico de pesquisa e a clínica: reflexões no contexto da Universidade. Revista Latinoamericana de Psicopatologia Fundamental, 15(3), 838-850.

Editor do artigo/Editor: Prof. Dr. Manoel Tosta Berlinck

Recebido/Received: 4.10.2011/10.4.2011 Aceito/Accepted: 13.7.2011 / 7.13.2011

Rev. Latinoam. Psicopat. Fund., São Paulo, v. 15, n. 4, p. 838-850, dezembro 2012 
Copyright: (C) 2009 Associação Universitária de Pesquisa em Psicopatologia Fundamental/ University Association for Research in Fundamental Psychopathology. Este é um artigo de livre acesso, que permite uso irrestrito, distribuição e reprodução em qualquer meio, desde que o autor e a fonte sejam citados / This is an open-access article, which permits unrestricted use, distribution, and reproduction in any medium, provided the original author and source are credited.

Financiamento/Funding: O autor declara não ter sido financiado ou apoiado / The author has no support or funding to report.

Conflito de interesses/Conflict of interest: $O$ autor declara que não há conflito de interesses / The author declares that has no conflict of interest.

\section{Nadja Rodrigues de Oliveira}

Mestre em Psicologia Clínica e Cultura (PPG-PsiCC) pela Universidade de Brasília - UnB (Brasília, DF, Br); Psicóloga pela mesma universidade; Pesquisadora do Laboratório de Psicopatologia e Psicanálise do Instituto de Psicologia da Universidade de Brasília - UnB. SHIN QI 08 CONJ. 05 CASA 05, Lago Norte 71520-250 Brasília, DF, Br.

e-mail: nadja.rodrigues@gmail.com

\section{Maria Izabel TAFURI}

Psicanalista; Doutora em Psicologia Clínica pela Universidade de São Paulo - USP (São Paulo, SP, Br); Professora Adjunta de Psicologia Clínica na Universidade de Brasília - UnB (Brasília, DF, Br); Coordenadora do Laboratório de Psicopatologia e Psicanálise do Instituto de Psicologia da Universidade de Brasília - UnB.

SHIN QL 15, CONJ. 9 CASA 18, Lago Norte

71535-295 Brasília, DF, Br

e-mail: izabeltafuri@gmail.com 